\title{
ESTRESSE TRAUMÁTICO SECUNDÁRIO: COMO INTERFERE NA ATUAÇÃO DO PROFISSIONAL DE ENFERMAGEM
}

\section{ARTIGO ORIGINAL}

COSTA, Sílvia Souza Lima ${ }^{1}$

CAJUEIRO, Laiza Pereira ${ }^{2}$

CARRIJO, Lucilene Santos Pereira ${ }^{3}$

RODRIGUES, Karen Lúcia Abreu 4

COSTA, Sílvia Souza Lima. Et al. Estresse Traumático Secundário: Como interfere na atuação do profissional de enfermagem. Revista Científica Multidisciplinar Núcleo do Conhecimento. Ano 06, Ed. 01, Vol. 07, pp. 38-56. Janeiro de 2021. ISSN: 2448-0959, Link de acesso: https://www.nucleodoconhecimento.com.br/saude/estresse-traumaticosecundario

${ }^{1}$ Acadêmica do curso de Enfermagem da Faculdade Morgana Potrich (FAMP), Mineiros - GO, Brasil.

2 Acadêmica do curso de Enfermagem da Faculdade Morgana Potrich (FAMP), Mineiros - GO, Brasil.

${ }^{3}$ Acadêmica do curso de Nutrição da Faculdade Morgana Potrich (FAMP), Mineiros GO, Brasil.

4 Orientador. Profa . Esp. Psicologia pela Faculdade Morgana Potrich (FAMP), Mineiros-GO. Docente da FAMP - Faculdade Morgana Potrich, Mineiros-GO. Brasil, graduação em Psicologia pela UFMT- Universidade Federal de Mato Grosso, especialização em Gestão organizacional, Desenvolvimento Humano e Coaching pela Avilá Pós- Goiânia, Gestão de Sala de Aula no Ensino Superior pela Unifimes Mineiros. 


\section{RESUMO}

A atuação do profissional de Enfermagem sofre com as interferências do Estresse Traumático Secundário (ETS), estresse laboral que acomete profissionais da área da saúde. O presente trabalho tem como objetivo conhecer as implicações do ETS na vida profissional, suas formas de prevenção e como intervir, afim de promover qualidade de vida laboral, que implica na saúde física e mental. Este estudo se deu por revisão bibliográfica de literatura, a partir da análise dos artigos e seleção de livros didáticos na área da Psiquiatria, com o intuito de solidificar o assunto e artigos científicos na base de dados da biblioteca virtual: Google Scholar, Pubmed, Scielo. Até que ponto o uso da empatia interfere no cotidiano do profissional? As profissões de ajuda sofrem com o efeito da aplicação dos sentimentos uma reação espontânea que ocorre ao fim da experiência de um acontecimento vivido por outro. É reputado como uma fadiga, proveniente do estresse ocupacional na sua fase de exaustão, levando a anestesia emocional. Estudos demostram que a reação do ETS se torna cumulativa, prejudicando a assistência prestada, gerando mudanças cognitivas, afetivas e relacionais, produzindo medo, tristeza e depressão. A literatura é escassa quanto a estudos referentes a esse assunto na Enfermagem, sendo imprescindível o desenvolvimento de estudos para maior esclarecimento do tema. O conhecimento e o monitoramento acerca do Estresse Traumático Secundário proporcionam atitudes preventivas, como meios de promover qualidade de vida, partindo do princípio de que a prevenção ainda é o melhor remédio para não adoecer.

Palavras-chave: Estresse, estresse traumático, Burnout, fadiga por compaixão.

\section{INTRODUÇÃO}

O Estresse Traumático Secundário (ETS) acomete as profissões de ajuda ao próximo em sofrimento, resulta da exposição prolongada à dor alheia e configura-se como uma reação espontânea vivenciada pelo profissional após o outro passar por uma experiência estressante; advém do estresse em sua fase aguda, de exaustão emocional, o que acaba por trazer prejuízos à vida do profissional (CASTRO, 2018). 
O estresse é entendido como uma resposta fisiológica do organismo diante de situações que levam o organismo a buscar modificações internas, requerendo uma resposta rápida individual no local em que ele está inserido. Uma adaptação a qual o prepara para enfrentar a agitação sendo uma mudança no comportamento, a fim de restabelecer um controle interno para o seu equilíbrio (TRETTENE, 2016).

A área da saúde é um lugar propício a desenvolver doenças nos profissionais devido ao estresse, desencadeando reações no organismo e promovendo adaptação momentânea. Produzindo assim, aumento da adrenalina, gerando energia no primeiro momento e estimulando um desempenho maior (VAZATA, 2015).

A longa duração do estresse leva a prejuízos físicos chegando a exaustão física e psicológica, a queda no desempenho da assistência e na própria saúde do trabalhador, demonstrando sensação de esgotamento, cansaço, como a Síndrome de Burnout, se o indivíduo não souber administrá-lo (MORAES, 2016).

O trabalho é uma parte indispensável da vida humana. É por meio dele que o homem pode viver e interagir na sociedade de produção. No entanto, as mudanças ocorridas nas últimas décadas acarretaram mudanças no ambiente de trabalho e, dependendo de como o trabalho é realizado, estará diretamente relacionado aos fatores e determinantes do desgaste durante o processo de adoecimento (TEIXEIRA, 2019).

A preocupação com a qualidade de vida no trabalho surgiu por volta da década de 1960, quando se percebeu que trabalhadores mais felizes e motivados produziam mais e melhor. Além de incentivar bons salários e benefícios atrativos, a qualidade de vida no trabalho consiste em um conjunto de técnicas e atividades que visam a satisfação dos colaboradores (SANCHEZ, 2019).

Os profissionais de saúde ao executarem suas funções através da empatia (compreensão emocional e identificação com outra pessoa) apresentam níveis de compaixão que podem levá-los a sentir medo, similar da dor e sofrimento alheio. Essa situação gera a fadiga por compaixão, uma árdua exaustão biológica que impede o organismo de liberar energia psíquica devido ao uso excessivo dos sentimentos de 
compaixão, levando ao Transtorno de Estresse Traumático Secundário (TEIXEIRA, 2019).

Considerando as consequências que podem desencadear do estresse, observa-se a importância de se detectar os sinais e sintomas em seu estágio inicial, interferindo de modo a impedir a sua evolução, pois os sintomas podem causar malefícios à saúde do profissional. Assim torna-se imprescindível conhecer, detectar, monitorar o quadro e intervir a fim de que o mesmo não evolua a uma exaustão emocional, o que leva ao Transtorno de Estresse Traumático Secundário.

Portanto esse estudo tem como objetivo conhecer os fatores que causam o Estresse Traumático Secundário (ETS) nos profissionais de Enfermagem, suas reações e o que pode ser feito na prevenção. Reconhecer a sua influência, entender os principais fatores que contribuem e identificar as implicações que dele advém; o valor na prevenção, conhecer o CID relacionado ao ETS e sua notificação; oferecendo alternativas laborais que contribuem para a qualidade de vida do profissional.

\section{METODOLOGIA}

O presente trabalho explana a revisão bibliográfica, método de pesquisa capaz de favorecer a associação do conhecimento e a integração de saberes expressivos para o entendimento de um tema ou fenômeno. (VIEIRA, 2018).

O primeiro passo se deu através da elaboração da pergunta norteadora do trabalho; no segundo buscou-se na base de dados e dos descritores assuntos ligados diretamente ao tema. Observou-se os resumos dos artigos envolvidos na pesquisa, selecionou esses artigos ligados ao tema. E por fim, realizou-se o cruzamento descritores das palavras-chave: Estresse. Estresse Secundário. Burnout. Fadiga por Compaixão. Estresse Pós-Traumático.

Dessa forma como meio de investigar o tema e solidificá-lo, foram incluídos no trabalho livros didáticos na área da Psicologia e Psiquiatria. 
Portanto, a revisão dos artigos foi realizada no período compreendido entre janeiro e março de 2020. A base de dados eletrônica Scielo, Google Scholar, Pubmed, Bases Bireme, Biblioteca Virtual em Saúde (BVS) foi utilizada para identificar e selecionar os artigos, definindo então os descritores e inserindo-os na pesquisa para inclusão. Os termos empregados foram separados e utilizados na busca dos Descritores. A partir das palavras-chave dos artigos envolvidos com o tema, efetivou-se por priorizar artigos brasileiros, a fim de conhecer o envolvimento acadêmico no assunto em questão. E como meio de envolver o contexto histórico incluiu-se artigo com a data além de cinco anos de publicação devido ao valor histórico.

\section{ESTRESSE}

O estresse é um processo interno do organismo que exige uma resolução multifacetada do sistema corporal incluindo modificações no comportamento humano. E decorre do acontecimento momentâneo requerendo reações cognitivas, emocionais para se adaptar ao meio, a fim de manter o equilíbrio interno diante da ameaça momentânea; cada indivíduo responde aos estímulos com características próprias gerando o seu próprio estresse (COSTA, 2016).

Os profissionais habilitados em enfermagem geralmente prestam serviços específicos ao atendimento da população fragilizada ou adoecida, carente de atendimentos médico hospitalar. Por isso, frente a essa demanda, os especialistas consomem energia física impulsionando o organismo à mudanças internas, extenuando as reservas funcionais através da queima de energia procurando adaptar ao meio produzindo o estresse (VAZATA, 2015).

Os trabalhadores que desempenham atividade em locais que requerem rapidez nas ações, conhecimento técnico científico e condutas minuciosas, como nos hospitais, apresentam graus de estresse elevados (PRETO, 2016).

As tarefas que devem ser realizadas em pouco tempo, barulho no ambiente, entre outros aspectos considerados causadores de estresse podem gerar sintomas como irritação, perda de atenção, sentimento de esgotamento, dor de cabeça, dor muscular, 
alterações na pressão arterial e batimentos cardíacos; essas alterações tendem a favorecer a evolução do estresse em profissionais da Enfermagem e acabam por agravar a má qualidade do sono, o que produz mais desgaste do que satisfação (VERSA, 2012; VAZATA, 2015).

Assim, aqueles que alcançam a satisfação no ambiente de trabalho tendem a ter baixo índice de estresse, evitando problemas de saúde física e psicológica, ao passo que a homeostase atingida pela grande quantidade de estresse gera tensões, o que pode acarretar no desgaste do organismo originando o esgotamento e comprometendo, então, a saúde do colaborador da equipe (GOMES, 2017).

Hans Selye é considerado o pioneiro a mencionar Estresse Biológico. Em 1925, como discente de medicina identificou ao receber a população com diversas patologias na clínica. Os sinais e sintomas como magreza inapetência, tônus musculares foi diminuído como respostas sendo comum em pessoas subjugadas à hostilidade. Assim, ele deliberou como uma "reação defensiva fisiológica do sistema em resposta a qualquer estímulo", dividindo-o em três fases: reação de alarme, de resistência e de exaustão (SILVA, 2018).

\subsection{FASES DO ESTRESSE}

$\mathrm{Na}$ fase de alarme, o estresse aparece insignificante, porém, o organismo proporciona a queima de mais energia a fim de manter a homeostase interna. Os batimentos cardíacos aumentam, a transpiração se eleva, ocorre a tensão muscular e o nervosismo, como respostas aos agressores (SILVA, 2018; VAZATA, 2015).

A segunda fase, é a de resistência, em que o organismo demanda as modificações internas aos estressores, consumindo as reservas orgânicas a fim de manter-se adaptado à nova situação. Apresentando assim, sinais como a inquietação, solidão, apreensão, inapetência ou gula; se os estressores forem contínuos o organismo enfraquecido passa para fase de exaustão, a terceira fase, em qual as doenças se manifestam em problemas cardíacos, respiratórios, distúrbios gastrointestinais, pois, o organismo não consegue se adaptar (SILVA, 2018). 
Para Vazata (2015), a exaustão é "quebra total de resistência", gerando as enfermidades. Desse modo, os sujeitos que lutam internamente podem desenvolver o processo de enfrentamento, utilizando o mecanismo de fuga como decorrente da fragilidade do organismo.

\subsection{EMPATIA}

Segundo Terezam (2017), a empatia é a capacidade de se posicionar no lugar das pessoas, com finalidade de idealizar e vivenciar na mesma concepção a experiência sofrida por outra (s). Comportamento importante para o aconchego, segurança, tranquilidade física e mental de ambas as partes envolvidas. A consciência dos próprios receios, assimilação das emoções e os sentimentos declarados pelo paciente favorecendo uma relação empática.

Segundo Savieto (2016), a empatia estabelece-se como a eficiência de analisar os sentimentos de outras pessoas. Se pôr na situação de cada pessoa, compreender suas concepções e emoções. Assim, os profissionais da saúde como as enfermeiras com competências empáticas podem compreender o paciente e estabelecer uma assistência para melhoria de vida.

No entanto, a equipe de Enfermagem deve conservar um grande nível de sensatez, persistência emotiva e compreensão, para que decorra a empatia como um processo terapêutico. E é primordial que se adiante uma ligação de respeito recíproco e que o enfermeiro realize os cuidados individualizados, respeitando a etnia, crenças e moral do cliente (ALBUQUERQUE, 2019).

Segundo Gambarelli (2018), por meio da assistência vivenciada entre o enfermeiro e paciente, este especialista pode determinar objetivos e propósitos a serem alcançados para o cliente, por ele próprio ou em equipe, de forma a acomodar o paciente e a estar conforme o ser humano integro, capaz de alcançar resultados para suas dificuldades. O paciente deve acatar desses especialistas o que for fundamental para o progresso e reabilitação de sua saúde. 


\subsection{SÍNDROME DE BURNOUT}

O Burnout é um processo gradual seguido de recusas durante a prática do exercício profissional gerando apatia, insensibilidade, falta de atividade e reação, oriundos do estresse frequente no labor. Inicia-se, então, atitudes negativas diante dos clientes como uma defesa deixando a afetividade e passando a agir de modo lógico racional, a fim de não ser atingido pelos estressores (OLIVEIRA; RODRIGUES; SANTANA, 2017).

A Síndrome de Burnout indica a exaustão da mente em relação ao exercício. Trata-se de um sentimento de fracasso e de esgotamento decorrido pelo desgaste excessivo dos profissionais. É gerada no envolvimento com pessoas e causada pelo trabalho, a qual torna o profissional desanimado, com baixo rendimento, falta de autoestima e declínio profissional. Pois eles se sentem impotentes e sem prazer em realizar seu trabalho (BENEDITO, 2017).

Visto que o contato contínuo e direto com o sofrimento da morte de pacientes exige do profissional um alto conhecimento a respeito de suas habilidades. Além de haver alta exigência no ambiente hospitalar na tomada de decisões e também tem influência direta na vida de outros. Essa carga de responsabilidade gera reações e sintomas individuais, surgindo por conta dos níveis de pressão e estresse existentes no ambiente. Em última instância, leva a um estado de esgotamento físico e mental. (FREITAS, 2017).

Na Síndrome de Burnout o profissional passa por experiências de esgotamento físico e emocional, devido à exaustão acarretada pelo exercício profissional. Além de enfraquecimento físico e reações emocionais, levando a sensações de despreparo e comportamentos negativos no ambiente laboral, distanciamento dos clientes, adoecimento dos profissionais que o acompanham, crescimento do absenteísmo e aumento dos custos com saúde para a empresa podendo gerar a decisão de trocar de profissão por quem passa pela Síndrome. (RUBACK, 2018). 


\subsection{O ESTRESSE TRAUMÁTICO SECUNDÁRIO}

O Estresse Traumático Secundário (ETS) decorre do atendimento a indivíduos em sofrimento, resultante do estresse na sua fase de exaustão emocional, gerado pela vivência de situações que outra pessoa vivencia e o profissional participa no atendimento. Produzindo assim, sintomas semelhante aos do padecente, repercutindo na sua própria atuação e sentimento (CASTRO, 2018).

Entretanto, uma reação espontânea que ocorre no profissional de ajuda (enfermeiros, médicos, bombeiros, policiais) decorrente do desfecho da experiência sobre um acontecimento vivido por outrem. Por exemplo, um trauma indireto, com efeito cumulativo no que presta socorro ou assistência, provocando um feedback, resposta de medo, impotência ou horror (VALENTE, 2013).

Ainda o Estresse Traumático Secundário pode indicar "fadiga por compaixão" relacionada à destruição progressiva da empatia que é capaz de atingir os especialistas de saúde. No início de suas profissões, esses especialistas apresentam grande grau de empatia. No entanto, pode ser reduzido pelo estresse do dia a dia causado pela exibição continua do sofrimento dos doentes (TEREZAM, 2016). O ETS possui sinônimos como "tensión traumática secundária, traumatización secundária, traumatización vicária, sobrevivente secundário, contágio emocional, fadiga por compassión" (RUIZ, 2017).

O ETS acomete grupo de profissionais cuidadores que lidam com o sofrimento alheio, como: risco de morte, enfermos ou vitimados por eventos traumáticos. Pois, podem ser contagiados pela dor real do outro, chegando a exaustão por compaixão decorrente da sensibilidade e cuidado a outrem. Gerando assim, ao longo do tempo declínio em sua habilidade de experimentar alegria ou sentir preocupação com alguém (BARBOSA, 2014).

Contudo o ETS é gerado pelo envolvimento do profissional que vivencia a dor alheia. Essa tal atuação produz sintomas de Transtorno de Estresse Pós-Traumático (TEPT), semelhante à do padecente, decorrente do empreendimento de pretender ajudar o ser 
humano em sofrimento, repercutindo negativamente no psíquico cognitivo do profissional (CASTRO, 2018).

envolvimento dos profissionais enfermeiros durante a sua jornada de trabalhos coloca-os diante de sobrecargas biopsicológicas. E o modo como cada indivíduo reage a essas tensões pode produzir uma diminuição na sua produtividade, levando ao adoecimento e às faltas no serviço (FELLI, 2015).

\subsection{SINTOMAS ESTRESSE TRAUMÁTICO SECUNDÁRIO}

O sintoma do Estresse Traumático Secundário surge após o profissional da saúde atender pessoas fragilizadas pelos sentimentos da empatia envolvido na assistência prestada, em que ele passa a sentir a dor alheia mesmo sem ter sofrido o dano. Esse sentimento recebe o nome de Estresse Traumático Secundário, porque modifica a homeostase interior do profissional. Todavia, as primeiras análises desse sentimento se deram nos parentes dos veteranos de guerra, em 1974, quando os familiares envolvidos sentiam a sintomatologia mesmo não estando no desempenho da guerra. Porém, entendeu-se, que a experiência traumática em pessoas saudáveis pode desenvolver reações sintomáticas do TEPT após a experiência a um determinado fato (APOIAR, 2017).

Segundo a $5^{\mathbf{a}}$ edição do Manual Diagnóstico e Estatístico de Transtornos Mentais (DSM-5), os eventos traumáticos desencadeiam nas pessoas envolvidas ou nas pessoas que estiveram próximas, vivenciando o acontecimento. As reações de evitações, excitabilidade, alterações negativas no humor e na cognição, produzindo sofrimento psicológico, queda no convívio social e profissional, conhecidos como Transtornos Relacionados a Trauma e a Estressores (ARAÚJJO, 2014).

É necessário que os sintomas apresentados estejam ligados ao episódio estressor traumático, vivenciado, testemunhado ou confrontado diante de um ou mais fatores que envolvam morte, grave ferimentos reais ou amedrontamento na sua plenitude na devida pessoa ou outrem. Como perda de algum membro do corpo em acidentes automobilísticos ou no trabalho, estupro, tortura física, bandidismo violento, 
explosões, e os acontecimentos naturais; enchentes, ataques por animais, terremoto, erupção vulcânica. Essas situações conduzem ao medo, descrença, desespero, desilusão (APOIAR, 2017).

\subsubsection{MODIFICAÇÕES NO PROFISSIONAL DECORRENTES DO ESTRESSE TRAUMÁTICO SECUNDÁRIO}

Durante a execução e o desenvolvimento do exercício da Enfermagem, o corpo do profissional sofre mudanças relacionadas ao estresse e a cada fase do mesmo, conhecido como o Estresse Ocupacional. Este tipo de estresse gera manifestações psicológicas em cada indivíduo decorrente do estresse na sua fase de exaustão. Segundo Fabri, 50\% dos profissionais manifesta desejo de evasão, $50 \%$ agonia e apreensão diária, além de $45 \%$ relatarem fadiga desmoderada conduzindo à fragilidade do organismo (FABRI, 2018).

Dessa foram o sofrimento provoca no corpo uma reação disfuncional biológica, enquanto resultado da exposição prolongada à dor do outro. A denominada fadiga por compaixão, em consequência da empatia, de responsabilidade para com o doente e seu sofrimento, um esvanecimento crônico do cuidado e da preocupação com o outro (SANTANA, 2017).

Os eventos traumáticos transformam as sensações no profissional após a experiência, geram medo e trauma, alteram o cognitivo, modificam a resposta e reações fisiológicas. As lembranças do trauma induzem ao amedrontamento, os quais levam à fuga, como proteção diante de um estressor, a fim de manter uma homeostase, pois o trauma provoca ansiedade (SBARDELLOTO, 2012).

Assim as modificações cognitivas aparecem como pensamentos intrusivos, hipervigilância, dificuldades de concentração, perda do sono, ideias fixas e sobrevalorizadas do perigo na sociedade. Como lembranças de imagens desagradáveis, entre outras. Tudo isso acaba por desencadear preocupações excessivas com a família e desesperança no seu cotidiano. No nível afetivo produz medo, ansiedade, intranquilidade, irritabilidade, ira, tristeza, melancolia, culpa e 
insensibilidade. E no nível fisiológico, náuseas, fadiga, calafrios, dor de cabeça, taquicardia, cefaleia, transtornos digestivos (RUIZ, 2017).

Portanto os sintomas de origem psicóticas podem aparecer em profissionais com a mente esgotada. Repercutindo no dia a dia como a sensação de esgotamento, tristeza, desânimo, diminuindo assim, a capacidade cognitiva, interferindo na qualidade do sono e produzindo ansiedade, sendo estes aumentados durante o labor diário (ALVES, 2015).

\subsection{MONITORAMENTO DO PROFISSIONAL}

O SISMOTE (Sistema de Monitorização Do Trabalhador de Enfermagem) é um sistema que foi desenvolvido e aprovado a fim de compreender os agravos nos profissionais da saúde, por meios de indicadores. A fim de apresentar o perfil de fragilidade dos trabalhadores e sendo possível o planejamento de intervenções com o intuito de minimizar as circunstâncias de episódios laborais degradantes (FELLI, 2015; GUIMARÃES, 2016).

O CEREST (Centro de Referência em Saúde do Trabalhador) é um órgão que atua desde 2004. Especialista no cuidado à vitalidade do colaborador, usufrui do modelo da Atenção Básica, conectada à Rede Nacional de Atenção Integral à Saúde do Trabalhador - RENAST, analisando os atores que implicam na saúde do trabalhador (CEREST, 2015).

Dessa forma, o CEREST tem por objetivo minimizar os acidentes e agravos oriundos do labor na vida do profissional, através de intervenções na área em desenvolvimento. Como, recuperação, precaução na esfera da saúde, contém informações sobre a Saúde do trabalhador, e é estruturado com ações de habilitação dos colaboradores. Tem a RENAST como uma das táticas para certificar a atenção integral a saúde dos trabalhadores, como uma das diretrizes da Política Nacional de Saúde do Trabalhador do Ministério da Saúde. Apresentando, então o propósito de constituir a rede de serviços do SUS, movidos à cooperação e observação das práticas de Saúde do Trabalhador através da prevenção e vigilância (CEREST, 2015). 
As alterações no profissional decorrida pelo estresse no dia a dia da profissão que levam ao estresse ocupacional dando o estresse secundário podem ser enquadrados segunda a Classificação Internacional de Doenças: CID-10, no CID F.43, por possuir em sintomatologia semelhante ao Transtorno de Estresse Pós-Traumático (TEPT). Essa padronização dos sinais e sintomas através do CID são universais, facilitando a sua monitorização através da padronização (CID 10, 1996).

Portanto o esgotamento do profissional pode levar à instabilidade psíquica, originando o transtorno mental, prejudicando a execução das tarefas no seu dia a dia. A literatura acerca dos transtornos na Enfermagem é escassa, e segundo Alves, os transtornos mentais constituem $12 \%$ das inabilidades na humanidade, sendo difícil o seu reconhecimento precoce por ser indefinida (ALVES, 2015).

\subsection{QUALIDADE DE VIDA NO TRABALHO}

Para favorecer o desenvolvimento de uma qualidade de vida satisfatória, o ambiente de trabalho necessita oferecer suporte social, segurança, bom salário, carga horária adequada, reconhecimento dos profissionais e oportunidades de crescimento. A qualidade de vida no trabalho é definida como um aspecto importante na decisão do enfermeiro de permanecer no emprego, mantendo-se qualificado, satisfeito e produtivo (HIPÓLITO, 2016).

A qualidade de vida no trabalho está relacionada a uma série de ações realizadas pela empresa que devem proporcionar condições adequadas de trabalho. Como, desenvolvimento humano, bom relacionamento interpessoal e felicidade dentro e fora da empresa. Assim, no entendimento de que isso ajuda a aumentar a produtividade dos colaboradores, proporciona disposição e motivação por meio dos quais os colaboradores podem alcançar resultados marcantes (SANCHEZ, 2019).

Enquanto a falta de motivação, o estresse elevado e o ambiente de trabalho desagradável são alguns dos principais motivos da má qualidade de vida na empresa. Como resultado, a organização pode ser prejudicada com altas taxas de absenteísmo e licenças médicas. Com a aplicação de princípios de qualidade de vida no trabalho, 
os funcionários se beneficiarão com condições de trabalho mais saudáveis, além da devida atenção à sua saúde e segurança, e o benefício é a melhoria da saúde física, mental, emocional e redução das doenças ocupacionais (HIPÓLITO, 2016).

\subsection{O ENFERMEIRO}

O enfermeiro é responsável por articular as ações e as suas decisões a fim de usar a tecnologia a favor do bem-estar do cliente, destacando-se como líder na assistência prestada na equipe, através do gerenciamento e envolvendo suas práticas e conhecimento adquiridos na sua formação, qualificação e agravos, produzindo promoção e recuperação da saúde (COFEN, 2020).

A atuação da Enfermagem é notória desde o Atendimento Pré-hospitalar Móvel Terrestre e Aquaviário, a assistência direta e Central de Regulação das Urgências, minimizando os riscos de doenças, no salvamento administração de medicamentos, transporte de pacientes, na sistematização da assistência por meio da implantação do processo de enfermagem (COFEN, 2020).

A área da Enfermagem é de extrema importância para o paciente e a sociedade, visando garantir e oferecer o direito à saúde e à vida. Nesse contexto, é necessário reconhecer que todos têm direito à assistência de Enfermagem adequada, de forma humanizada, integrada e caridosa (FROTA, 2019).

O Enfermeiro está aliado à qualidade do atendimento prestado graças ao envolvimento com os pacientes e familiares. A profissão faz parte de um eixo extremamente importante no processo de adoecimento e hospitalização, onde o vínculo criado é de confiança, auxiliando, nos casos de fragilidades dos pacientes (FROTA, 2019).

O Enfermeiro pode ser influenciado pelo sofrimento alheio, chegando a exaustão por compaixão decorrente da atuação profissional no cuidado. Gerando assim, ao longo do tempo diminuição da empatia e de experimentar alegria ou sentir preocupação com alguém (BARBOSA, 2014). 
Ao atender pessoas fragilizadas, o contato com a dor alheia, pode desencadear no profissional Enfermeiro o Estresse Traumático Secundário no decorrer dos anos (CASTRO, 2018).

\section{RESULTADOS E DISCUSSÃO}

O ETS advém do estresse na sua fase de exaustão emocional, decorrente dos sentimentos envolvidos pela empatia e pela compaixão. Nos atendimentos as pessoas fragilizadas em momento de dor, podendo ser em acidentes ou tortura, acontecimentos naturais (enchentes, terremotos, erupção vulcânica), situações que proporcionam medo, impotência e desespero (RISSARDO, 2013; APOIAR, 2017).

Segundo Ruiz (2017), o ETS representa as emoções que emergem no profissional após prestar atendimento em pessoas que passaram por situações dolorosas, resultante da empatia na interação profissional, em que o profissional passa por alterações no organismo levando ao desgaste emocional e está ligado ao estresse ocupacional.

Todavia os fatores que causam o Estresse Traumático Secundário nos profissionais de Enfermagem advêm do desgaste psicológico explícito nas funcionalidades orgânicas do ser humano, cujo envolvimento da atuação técnica junto à condição do paciente somado a dupla jornada de trabalho, família, atividades rotineiras e funções que requerem empenho corpóreo e psíquico predispõe o trabalhador da saúde ao ETS (SANTANA, 2017).

$O$ ato de negar os sintomas diz respeito a uma recusa consciente na percepção de fatos perturbadores, o que gera os comportamentos de defesa, entre eles o isolamento, a recusa. Gerando assim perturbações nas relações estabelecidas no trabalho, os quais podem prejudicar todos os âmbitos da vida do profissional (FREIRE, 2017).

No entanto no trabalho, cada profissional tem a sua individualidade e modo de adaptação no meio inserido, cujas reações podem conduzir a enfermidades futuras 
dependendo da fase do estresse. Pois, o organismo não consegue se adaptar à demanda das reações internas e emocionais reais no local de ocupação ou vivência (GOMES, 2017).

O Burnout está conectado à exigência de responsabilidade no trabalho, associado à complexidade de efetuar funções dentro de regimes afadigados, ofegante e desfavorecido de meios (APOIAR, 2017). Afeta-se colaboradores que lidam com pessoas e atividades relacionadas ao público, e ocorre pela dinâmica do ofício (RODRIGUES; SANTANA, 2017).

Algumas mulheres, frequentemente, demostram com mais facilidade as suas emoções, por isso recebem as precauções de ajuda emotiva. Já os homens são o oposto, normalmente aceitam pouco o cuidado. Essa eficiência das mulheres em dar maior valor às sensações é um processo fundamental para os enfermeiros. $O$ qual concede uma compreensão dos sentimentos, promovendo uma grande cooperação do estado do paciente, o que se liga com a empatia (MUFATO, 2019)

Entretanto o sentimento ao próximo é diminuído, conhecido como anestesia emocional, atenuação da disposição ou atividades antes prazerosas, como queda no envolvimento que antes trazia sobre si compaixão e amabilidade. (VALENTE, 2013).

No Brasil o fenômeno ETS é pouco conhecido. Assim, baseando os estudos na obra de Kennyston Lago e Wanderley, sob o olhar da enfermagem (SANTANA, 2014), são encontradas obras diretamente ligadas ao tema em outros idiomas, como, inglês e espanhol (LORENZO, 2017).

Ruiz (2017) afirma que o Estresse traumático Secundário é um tema novo que possui potencial para interferir na execução das tarefas diárias durante a jornada de trabalho e influência no desenvolvimento de quadros depressivos. Modificando assim, as reações cognitivas, fisiológicas e a sua própria conduta. Desenvolvendo então, o evitamento como meio de proteção no seu subconsciente, causando desmotivação das atividades antes prazerosas e aumentando a sensação de desgaste, pois como meio de tentar evitar a ocorrência vivida, se dedica a trabalhar incessantemente. 
Segundo Teixeira, o estresse indica imposição, provocando o esmorecimento do profissional enfermeiro, influenciando na homeostase de seu corpo, por motivo da enorme acumulação de tensões que ocorre no cotidiano (TEIXEIRA, 2019).

A empatia é uma habilitação que consegue ser exercida diante do paciente de forma oral e não oral. E sua progressão é de grande importância, pois é por meio dela que nos dispomos a colaborar com as pessoas (ALBUQUERQUE, 2019).

Segundo Guimarães (2016), há dificuldade em monitorar a saúde do enfermeiro pela insuficiência de anotações nas organizações sobre os danos processados. Sendo a monitorização do bem-estar e vitalidade do colaborador de enfermagem um grande desafio. Haja visto que os transtornos mentais desenvolvidos pela execução do trabalho foram notificados como situações de depressão e ansiedade, oriundos do desgaste emocional, representação de uma requisição da psique do trabalhador que não tinha suporte grupal. Sendo possível o seu evitamento através de medidas preventivas e protetoras.

Assim o apoio psicológico e o apoio social, segundo Ruiz (2017), são fundamentais para que o profissional possa enfrentar situações de emergência sem desenvolver o ETS. Pois a carga laboral sem o suporte possui efeito negativo em todos os outros âmbitos da vida do profissional, diminuindo a capacidade de enfrentamento.

A psicoterapia é um meio de cuidado no qual através da comunicação verbal, o diálogo, é possível verificar a queixa e os problemas do profissional, relacionados a sua profissão, interferindo de um modo a modificar o problema originado pelas emoções, comportamento e o cognitivo. Protegendo assim, o seu emocional, ajudando no fortalecimento das reações, através do diálogo entre os profissionais e o enfermeiro gestor do local, a fim de encontrar meios específicos que mantenham o equilíbrio emocional, diminuindo os riscos de produzir as doenças através do estresse (GUIMARÃES, 2016). 


\section{CONSIDERAÇÕES FINAIS}

Respeitar o limite do corpo, conhecendo as suas fragilidades pode contribuir para a diminuição do estresse, proporcionando satisfação durante a atuação do profissional e evitando o desgaste na fase de exaustão que gera alterações no organismo e na mente, modificando o sentimento envolvido na execução, a empatia, originando o ETS. Ofertar ao profissional condições psíquicas favoráveis ao atendimento sadio de si próprio produz, então, uma assistência qualificada, pois o Enfermeiro também é um ser humano com fragilidades que podem interferir no seu cotidiano da profissão; as sobrecargas diárias podem danificar a qualidade da assistência prestada, aumentando o estresse diário e prejudicando a qualidade de vida.

Assim, para que o profissional tenha boa saúde física ou mental, deve haver um ambiente agradável, o que por sua vez proporciona uma boa qualidade de vida, diminuindo os fatores desencadeantes do estresse que promovem o Estresse Traumático Secundário nos profissionais de Enfermagem.

Conclui-se com essa pesquisa que o estresse na fase de exaustão proporciona o aparecimento da Síndrome de Burnout e o Estresse Traumático Secundário, tornando o monitoramento do profissional importante, pois contribui de modo significativo às intervenções referentes a fragilidades individuais, de modo a diminuir o estresse oxidativo, contribuindo assim para uma melhor qualidade de vida e um profissional que oferte uma assistência qualificada.

\section{REFERÊNCIAS}

ALBUQUERQUE, M. C.S. et al., NURSES' EMPATHY IN AN EMERGENCY HOSPITAL SERVICE. Texto context - enferm., Florianópolis, v. 28, e20170406, 2019. Disponível em: <http://www.scielo.br/scielo.php?script=sci_arttext\&pid=S0104$07072019000100327 \&$ Ing=en\&nrm=iso >. Acesso em 03 mar. 2020.

ALVES, A. P. et al. Prevalência de transtornos mentais comuns entre profissionais de saúde [Prevalence of common mental disorders among health professionals]. Revista 
Enfermagem UERJ, [S.I.], v. 23, n. 1, p. 64-69, mar. 2015. ISSN 0104-3552. Disponível em:

$<$ https://www.epublicacoes.uerj.br/index.php/enfermagemuerj/article/view/8150/12330>. Acesso em: 08 ago. 2020.

APOIAR, ASSOCIAÇÃO DE APOIO AOS EX-COMBATENTES VÍTIMAS DO STRESS DE GUERRA. Artigo Científico. Conceito de Traumatização Secundária. Faculdade de Psicologia e Ciências da Educação da Universidade de Lisboa. 19, set. 2017. Disponível em: <https://apoiarstressdeguerra.com/pt/2013/04/01/tese-de-mestrado-em-perturbacao-secundaria-destress-traumatico-stsd/>. Acesso em: 26 fev. 2020.

ARAUJO, A. C.; LOTUFO NETO, F.; A nova classificação Americana para os Transtornos Mentais: o DSM-5. Rev. bras. ter. comport. cogn., São Paulo, v. 16, n. 1, p. 67-82, abr. $2014 . \quad$ disponível em <http://pepsic.bvsalud.org/scielo.php?script=sci_arttext\&pid=S151755452014000100007\&lng=pt\&nrm=iso>. Acessos em 24 fev. 2020.

BARBOSA, S.C; SOUZA, S.; MOREIRA, J.S.; A fadiga por compaixão como ameaça à qualidade de vida profissional em prestadores de serviços hospitalares. Rev. Psicol., Organ. Trab., Florianópolis, v. 14, n. 3, p. 315-323, set. 2014. Disponível em: <http://pepsic.bvsalud.org/scielo.php?script=sci_arttext\&pid=S198466572014000300007\&lng=pt\&nrm=iso>. Acesso em: 11 jan. 2020.

BARRETO, J.B.M; CAMPOS, C.A.; A psicoterapia de apoio como método para atender à demanda de queixa nos relacionamentos interpessoais: um estudo de caso. Pesquisa Em Psicologia - Anais eletrônicos, 21 - 23. 2016. Disponível em: < https://portalperiodicos.unoesc.edu.br/pp_ae/article/view/11914>. Acesso em: 29 ago. 2020.

BENEDITO, J. G. SÍNDROME DE BURNOUT EM ENFERMEIROS NA UNIDADE DE TERAPIA INTENSIVA: UMA REVISÃO NARRATIVA DA LITERATURA. Uma Revisão Narrativa da Literatura, Pernambuco, p.01-13, 2017. 
CASTRO, E. K.; MASSOM, T.; DALAGASPERINA, P. Estresse Traumático Secundário em Psicólogos. Revista Psicologia e Saúde, v.10, n. 1, p.115-125, 23 mar. 2018. Universidade Católica Dom Bosco. Disponível em: <http://dx.doi.org/10.20435/pssa.v9i3.554>. Acesso em: 10 fev. 2020.

CENTRO DE REFERÊNCIA EM SAÚDE DO TRABALHADOR- CEREST. Biblioteca Virtual Em Saúde. 2015. Disponível em: <http:// bvsms.saude.gov.br/dicas-emsaude/1086-centro-de-referencia-em-saude-do-trabalhador-cerest>. Acesso em: 30 ago. 2020 .

CEREST - APRESENTAÇÕES. POLÍTICA NACIONAL DE SAÚDE DO TRABALHADOR E DA TRABALHADORA. Vigilância em Saúde. Disponível em: $<$ https://www.vs.saude.ms.gov.br/cerest/apresentacoes-cerest/>. Acesso em: 23 ago. 2020 .

COFEN, Conselho Federal de Enfermagem. Resolução Cofen 633/2020. A Atuação dos profissionais de enfermagem no atendimento Pré-hospitalar (APH) móvel terrestre e Aquaviário, quer seja na assistência direta e na Central de fregulação das Urgências (CRU). Brasília, 24 de Març de 2020. Disponível em: $<$ http://www.cofen.gov.br/resolucao-cofen-no-06332020_78203.html\#: :text=Normatiza\%2C\%20\%E2\%80\%9Cad\%20referendum\%E2 \%80\%9D\%20do,Regula\%C3\%A7\%C3\%A30\%20das\%20Urg\%C3\%AAncias\%20(CR U)>. Acesso em 13 dez. 2020.

COSTA, C. A. C.; COSTA, V. L. S.; ESTRESSE OCUPACIONAL EM TRABALHADORES DA SAÚDE: FATORES DE RISCO E AGRAVOS GERADOS NO AMBIENTE DE TRABALHO: X Semana de Iniciação Científica da Faculdade R. Sá. Pi. jun. 2016.

FABRI, J. M.G.; NORONHA, I.R.; OLIVEIRA, E.B.; KESTENBERG, C. C. F., HARBACHE, L. M. A.; NORONHA, I. R Estres se ocupacional em enfermeiros da pediatria: manifestações físicas e psicológicas. Rev baiana enferm. V. 32, 25070. 2018.

Disponível em: 
ttps://portalseer.ufba.br/index.php/enfermagem/article/view/25070>. Acesso em: 30 ago. 2020.

FELLI, V. E. A; COSTA, T. F; BAPTISTA, P. C. P; GUIMARÃES, A. L. O; ANGINO, B.M. Exposição dos Trabalhadores de Enfermagem às Cargas de Trabalho e Suas consequências. Revista da Escola de Enfermagem da USP. 49. Pág. 98 - 105. 2015.

FREIRE, D. A. L; MARISA, A. E; Levantamento dos mecanismos de defesa dos profissionais de enfermagem frente à deterioração das condições de trabalho: Rev. Adm. Saúde Vol. 17, № 68, jul. - set. 2017. Acesso em: 19 fev. 2020.

FREITAS, R. J. M., et al. Estresse do enfermeiro no setor de urgência e emergência. Revista de Enfermagem UFPE on line- ISSN:1981-8963, v. 9, n. 10, p. 1476-1483, nov. 2015. ISSN 1981-8963. Disponível em: $<$ https://periodicos.ufpe.br/revistas/revistaenfermagem/article/view/10861>. Acesso em: 07 fev. 2019.

GAMBARELLI, S. F; TAETS, G.G.C. C; Revisão A importância da empatia no cuidado de enfermagem na atenção primária à saúde. v. 17, n.4, 2018. Disponível em: <http://dx.doi.org/10.33233/eb.v17i4>. Acesso em: 02 mar. 2020.

FROTA, M. A. et al.; Mapeando a formação do enfermeiro no Brasil: desafios para atuação em cenários complexos e globalizados. Ciênc. saúde coletiva, Rio de Janeiro , v. 25, n. 1, p. 25-35, Jan. 2020 . Disponível em: $<$ http://www.scielo.br/scielo.php?script=sci_arttext\&pid=S1413$81232020000100025 \&$ Ing=en\&nrm=iso $>$. Acesso em: 15 dez. 2020.

GUIMARÃES, A. L. O; FELLI, V. E. A; Notificação de Problemas de Saúde em Trabalhadores de Enfermagem de Hospitais Universitários. Revista Brasileira de Enfermagem. Vol. 69. № 03 Brasília Maio/Junho 2016. <https://doi.org/10.1590/0034-7167.2016690313i>. Acesso em: 06 agos. 2020. 
GOMES, J.; SILVA, A. S.; BERGAMINI, G. B. SAÚDE E QUALIDADE DE VIDA: INFLUÊNCIA DO STRESS NO AMBIENTE DE TRABALHO: Revista Científica da Faculdade De Educação E Meio Ambiente FAEMA.v.8, n.2,207 - 220, Ariquemes, 2017. Disponível em: <https://doi.org/10.31072/rcf.v8i2.547>. Acesso em: 18 fev. 2020.

HIPÓLITO, M.C.V.; MASSON, V.A.; MONTEIRO, M. I.; GUTIERREZ, G. L. Qualidade de Vida no Trabalho: Avaliação de Estudos de Intervenção. Revista brasileira de Enfermagem [Internet]. 2016; 70 (1): 178-86. Acesso em: 21 setembro, 2020.

LOPES, E. R.; SOUZA, J. E. O. Conflitos na equipe de enfermagem: um desafio na gestão do enfermeiro.: Única Cadernos Acadêmicos. Contagem - MG, p.01-10, 2015. Disponível

em: $<$ http://co.unicaen.com.br:89/periodicos/index.php/UNICA/article/view/10>. Acesso em: 03 fev. 2020.

LORENZO, R. A; GUERRERO, A. A. E.; Afetações psicológicas em casos pessoais primários: ¿Trastorno por períodos pós-traumáticos ou períodos traumáticos secundários? Preocupações psicológicas nos socorristas: transtorno de estresse póstraumático ou estresse traumático secundário? Revista Puertorriqueña de Psicología, 28 (2), 252-265. 2017.

MORAES FILHO, I. M.; Estresse Ocupacional no Trabalho em Enfermagem no Brasil: Uma Revisão Integrativa: Revista Brasileira em Promoção da Saúde. V.29, n.3, p.447-454, ago. 2016. Disponível em: <https://www.redalyc.org/articulo.oa?id=40849134018>. Acesso em: 19 fev. 2020.

MUFATO, L. F; GAIVA, M. A. M; EMPATIA EM SAÚDE: REVISÃO INTEGRATIVA. Revista de Enfermagem do Centro Oeste Mineiro. 2019;9: e2884. Disponível em: <http://dx.doi.org/10.19175/recom.v9i0.2884>. Acesso em: 21 fev. 2020.

OLIVEIRA, E. B. et a. Estresse ocupacional e burnout em enfermeiros de um serviço de emergência: a organização do trabalho [Occupational stress and burnout in nurses of an emergency service: the organization of work]. Revista Enfermagem UERJ, 
[S.I.], v. 25, p. e28842, jun. 2017. ISSN 0104-3552. Disponível em: <https://www.epublicacoes.uerj.br/index.php/enfermagemuerj/article/view/28842/22382>. Acesso em: 25 fev. 2020.

Organização Mundial da Saúde. Classificação Estatística Internacional de Doenças e Problemas Relacionados à Saúde: CID-10 Décima revisão. Trad. Do Centro Colaborador da OMS para a Classificação de Doenças em Português. 3 ed. São Paulo: EDUSP; 1996.

PRETO, V. A.; PEDRÃO, L J. O estresse entre enfermeiros que atuam em Unidade de Terapia Intensiva. Revista da Escola de Enfermagem da Usp, v. 43, n. 4, p.841848, dez. 2016 FapUNIFESP (SciELO). Disponível em: <http://dx.doi.org/10.1590/s0080-62342009000400015>. Acesso em: 30 jan. 2020.

RISSARDO, M. P.; GASPARINO, R. C. Exaustão emocional em enfermeiros de um hospital público: Esc. Anna Nery, Rio de Janeiro, v.17, n.1, p.128132, mar. 2013. Available from $<$ http://www.scielo.br/scielo.php?script=sci_arttext\&pid=S141481452013000100018\&lng=en\&nrm=iso >. Acesso em: 17 fev. 2019.

RODRIGUES, C. P. Estresse e qualidade de vida em técnicos e auxiliares de enfermagem em instituições de longa permanência para idosos.: O Mundo Saúde, n. 2, v. 40, São Paulo, p.180-188, 2017.

RUBACK, S.P; TAVARES, J.M.A.B; LINS, S.M.S.B; et al. Estresse e Síndrome de Burnout em Profissionais de Enfermagem que Atuam na Nefrologia: Uma Revisão Integrativa. Rev Fund Care Online. 2018 jul. /Set.; 10(3):889-899. Disponível em: <http://dx.doi.org/10.9789/2175-5361.2018.v10i3.889-899>. Acesso em: 10 fev. 2020.

RUIZ, A. L; ANGELES, E. A. G. Afectaciones Psicológicas Em Personal De Primeira Respuesta: Transtorno Por Estrés Postraumático O Estrés Traumático Seundário? Revista Puertorriquena de Psicologia. V. 28. № 2. Pág. 252 -265. Julho - dezembro 2017. 
SANCHEZ, H. M. et al. Impacto da saúde na qualidade de vida e trabalho de docentes universitários de diferentes áreas de conhecimento. Ciência \& Saúde Coletiva [online]. v. 24, n. 11, 2019. Acessado 16 setembro 2020, pp. 4111-4123. Disponível em: <https://doi.org/10.1590/1413-812320182411.28712017>.

SANTANA, J. R.; RODRIGUES, C. C.; PEREIRA, S. F.; ANÁLISE DE CONTEÚDO DA OBRA FADIGA POR COMPAIXÃO, DE KENNYSTON LAGO E WANDERLEY CODO: SOB O OLHAR DA ENFERMAGEM: Revista Pesquisa E Ação, 3(1); (2017, junho 1). Recuperado de $<$ https://revistas.brazcubas.br/index.php/pesquisa/article/view/268>. Acesso em: 22 fev. 2020.

SAVIETO, R. M; RIBEIRO; LEÃO, E. R. Assistência em Enfermagem e Jean Watson: Uma reflexão sobre a empatia. Escola Anna Nery Revista de Enfermagem 2016, vol.20, n.1, pp.198-202. ISSN 1414-8145. 2020 Disponível em: <https://doi.org/10.5935/1414-8145.20160026>. Acesso em: 02 mar. 2020.

SBARDELLOTO, $G$ et al. Processamento Cognitivo no Transtorno de Estresse PósTraumático: Um Estudo Teórico. Interação em Psicologia, Curitiba, v. 16, n. 2, dez. 2012. ISSN 1981-8076. Disponível em: <https://revistas.ufpr.br/psicologia/article/view/18934>. Acesso em: 20 fev. 2020.

SILVA, D. P; SANTOS, N. R. O; NASCIMENTO, L.K.A.S; Fatores Que Influenciam o Estresse Ocupacional Na enfermagem: Revista Cultural e Científica do UNIFACEX. v. 14, n. 2, outubro de 2016.

SILVA, R. M; GOULART, C.T; GUIDO, L.A. Evolução histórica do conceito de estresse. Rev. Cient. Sena Aires. 2018; 7 (2): p. 148-156. Acesso em: 04 fev. 2020.

TEIXEIRA, G.S; SILVEIRA, R.C.P; MININELM, V.A; MORAES, J.T; RIBEIRO, I.K.S. Qualidade de vida no trabalho e estresse ocupacional da enfermagem em unidade de pronto atendimento. Texto Contexto Enferm 2019, 28: e20180298. Disponível em: <http://dx.doi.org/10.1590/1980-265X-TCE-2018-0298>. Acesso em: 27 Jan. 2020. 
TEREZAM, R.; REIS-QUEIROZ, J; HOGA, L. A. K. The importance of empathy in health and nursing care. Revista Brasileira de Enfermagem, v. 70, n. 3, p.669-670, jun. 2017. FapUNIFESP (SciELO). Disponível em: <http://dx.doi.org/10.1590/00347167-2016-0032>. Acesso em: 04 fev. 2020.

TRETTENE, A. S., et al. Estresse em profissionais de enfermagem atuantes em Unidades de Pronto Atendimento. Bol. - Acad. Paul. Psicol., São Paulo, v. 36, n. 91, p. 243-261, jul. 2016.

Disponível

em

$<$ http://pepsic.bvsalud.org/scielo.php?script=sci_arttext\&pid=S1415-

711X2016000200002\&Ing=pt\&nrm=iso >. Acesso em: 04 fev. 2020.

VALENTE, N. L. M; MELLO, M. F.; FIKS, J. P. Transtorno de Estresse pós-traumático. In: MARI, Jair de Jesus. Psiquiatria na Prática Clínica. Tamboré: Manole. p. 315326, Cap. 18, 2013.

VAZATA, D.; NEZI, T. C. O ESTRESSE E A PROFISSÃO DE ENFERMAGEM. Pesquisa em Psicologia - anais eletrônicos, 30 out. 2015. Disponível em https://portalperiodicos.unoesc.edu.br/pp_ae/article/view/8609> Acesso em 28 jan. 2020.

VERSA, G. L. G. S.; MURASSAKI, A. C. Y.; INOUE, K. C.; MELO, W. A.; FALLER, J. W.; MATSUDA, L. M. Estresse ocupacional: avaliação de enfermeiros intensivistas que atuam no período noturno. Rev Gaúcha Enferm. 33, p.78-85, jun. 2012.

VIEIRA, S.S.; AZEVEDO, I. R. P.; CASAGRANDE, J. L. Pesquisa Bibliográfica, Pesquisa Bibliométrica, Artigo de Revisão e Ensaio Teórico em Administração e Contabilidade. Administração: Ensino e Pesquisa. Vol.19, n. 2, 2018. Maio agosto, pg 308-339 Rio de Janeiro. Disponível em: <https://doi.org/10.13058/raep.2018.v19n2.970> Acesso em: 10 fev. 2020.

Enviado: Dezembro, 2020.

Aprovado Janeiro, 2021. 